\title{
Vocational School Art Teaching Research under the Support of Network Technology
}

\author{
Hongmei YAN $^{1,}$ a \\ ${ }^{1}$ Binzhou Polytechnic Institute of architectural engineering, Binzhou 256603, China \\ a Xiaoyu9423@126.com
}

Keywords: Network technology, vocational school art teaching, information technology

\begin{abstract}
Multimedia technology, optical fiber communication equipment, digital satellite communication system and other new information forms constantly open up new space for mankind. Information technology comes into every corner of society, and the world walks towards a highly integrated, as well as the instant message has become a new form of capital. Vocational school art teaching research based on information technology is the research, under the condition of information technology, of how to make the mutual harmony between information technology and vocational school art teaching integration in order to maximize effect of vocational school art teaching. On information technology and vocational school art curriculum integration of the two kinds of teaching modes, namely, information technology under the condition of the art research learning and information technology collaborative learning.
\end{abstract}

\section{The brief introduction of vocational school art teaching and information technology}

Information technology is an international express, countries have some differences on the concrete expression, and for example it is called information and communication technology in the basic education in Britain, short for ICT; whereas in France it is short for TIC, Technology of information and communication. Information technology is generally defined as the application of theories and methods of information technology for information acquisition, processing and application; it covers micro-electronics technology, computer technology, communication technology and sensor technology and becomes a comprehensive technology. It is obvious that, for basic education, information technology is the ability of acquisition, processing and application of information.

Art teaching is to teach students the knowledge and skills of fine arts by means of education. And develop and disseminate arts and culture, with the medium of art, by art teaching, cultivating students' moral sentiment, aesthetic ability, and the development of intelligence and creativity. The pursuit of the effect of general education and the complete understanding of the fine arts education are based on the complement of each other, on the basis of organic unity. The arts education teaching system has the following four elements: the teachers, students, curriculum, resources and technology. These four elements connect with each other, interact to form a stable form of teaching structure, and overall affect the teaching of the art. Student is the main body of teaching, the teacher is the lead of teaching. Student forms a direct corresponding relationship with curriculum as a learner with the teacher's leading role. Resources and technology are important aspects of the integral teaching system, and acts on teaching together with students, teachers and curriculum shown in chart1: 


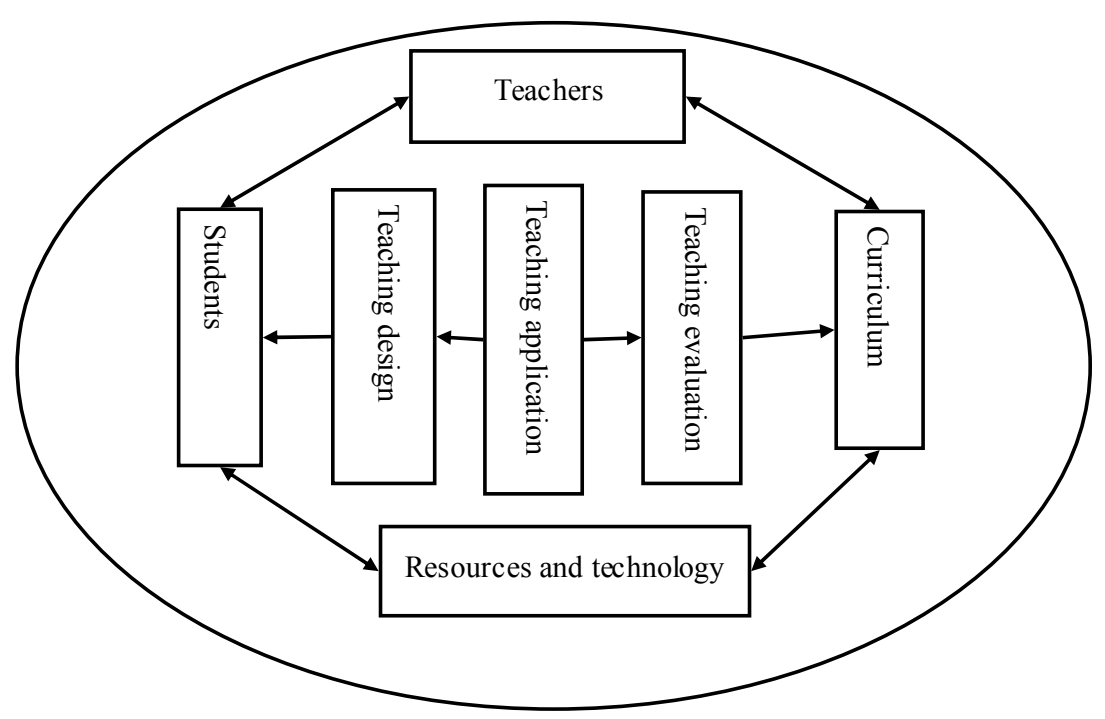

Chart 1: structure chart of art teaching elements

\section{Theory basis of vocational school art teaching based on information technology}

American education scholars Joe Exline said that the research learning is a kind of study way of exploration of the information and the truth, or looking for relevant information on problems. Research means to participate in, it also means that when constructing new knowledge, you have ability and the attitude to find a solution of the problem. The art theory of computer aided the research-oriented learning in the teaching is the multivariate structured theory (as shown in chart 2). The theoretical basis of computer-assisted teaching has three big evolutions.

\section{Behaviorism learning theory}

The theory of first evolution is based on behaviorism learning theory, from the beginning of $60 \mathrm{~s}$ to the end of $70 \mathrm{~s}$. This is the primary stage of computer-assisted instruction. In design of CAI courseware, branches of small steps of program design based on the box, over the years, have become the main mode of the development of CAI courseware, and is the obvious example of the influence of behaviorism.

\section{Cognitive learning theory}

The second stage is based on cognitive learning theory as the theoretical basis, from the late $70 \mathrm{~s}$ to 80s. This is the development stage of the computer aided teaching. In the design of CAI courseware, people begin to pay attention to learners' internal mental process, begin to study and emphasize learners' psychological characteristics and cognitive law. The network plan LAG calculating figure can be seen in figure 1 :

$$
\begin{aligned}
& F F_{i-j}=E T_{j}-E_{i-j} \\
& F F=\min \left[E_{j}-E F_{i}\right] \\
& L A G_{i, j}=E S_{j}-E F_{i}
\end{aligned}
$$

\section{Constructivism learning theory and teaching theory}

Third revolution is based on constructivism as the theory, from the early 90s till now, which is the mature stage of the computer aided teaching. Constructivism learning theory emphasizes on the student center, it requires students not only to transfer from the passive receivers of external stimulation and knowledge into the active constructors of the main body of information processing and knowledge meaning, and also requires teachers to transfer from imparter of knowledge to the helper and facilitator that students actively construct meaning. 


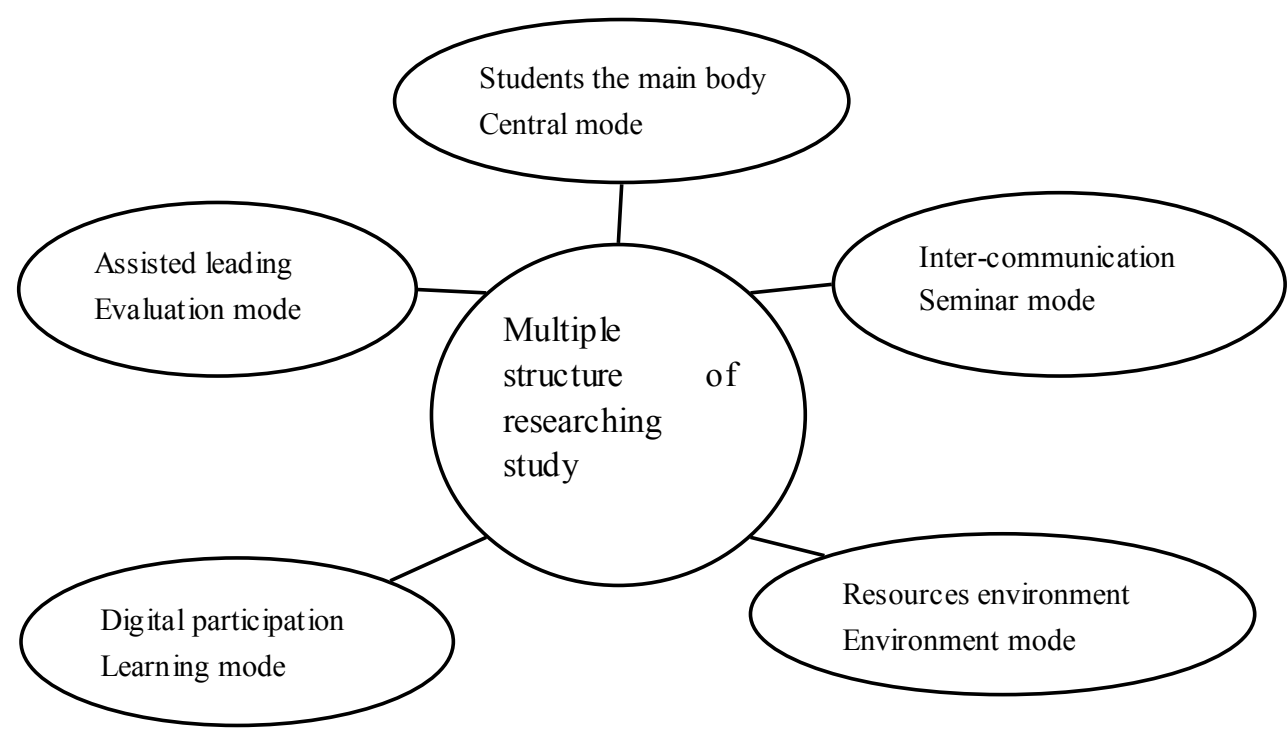

Chart 2: teaching theory of multiple structures

\section{The research of computer-assisted art teaching mode}

The emergence of computer aided technology plays an irreplaceable role for the fine arts education research learning, the importance for supporting art resources sharing platform, digital software and digital network and etc. And it creates the best learning environment for the fine arts teaching activities. And figure 2 is shown in the following

$$
\begin{aligned}
& E=\left(\triangle R+r E_{w}\right) /(\triangle+r) \\
& E=\left(\triangle R+r^{\prime} E_{R}\right) /\left(\triangle+r^{\prime}\right)
\end{aligned}
$$

Among which

$$
\mathrm{r}^{\prime}=\mathrm{r}+48 \mathrm{aT} 3 \mathrm{a} / \mathrm{LD}
$$

\section{Study on the model of traditional art teaching}

"Dual structured" teaching mode has long been regarded as the standard of fine arts teaching mode, the traditional arts teaching implementation process does not change too much. The present "dual structured" teaching mode can meet the requirements of art teaching practice, the specific operation, in line with the laws of art theory to guide teaching practice. The "Dual structured" teaching mode can be seen in the following chart 3:

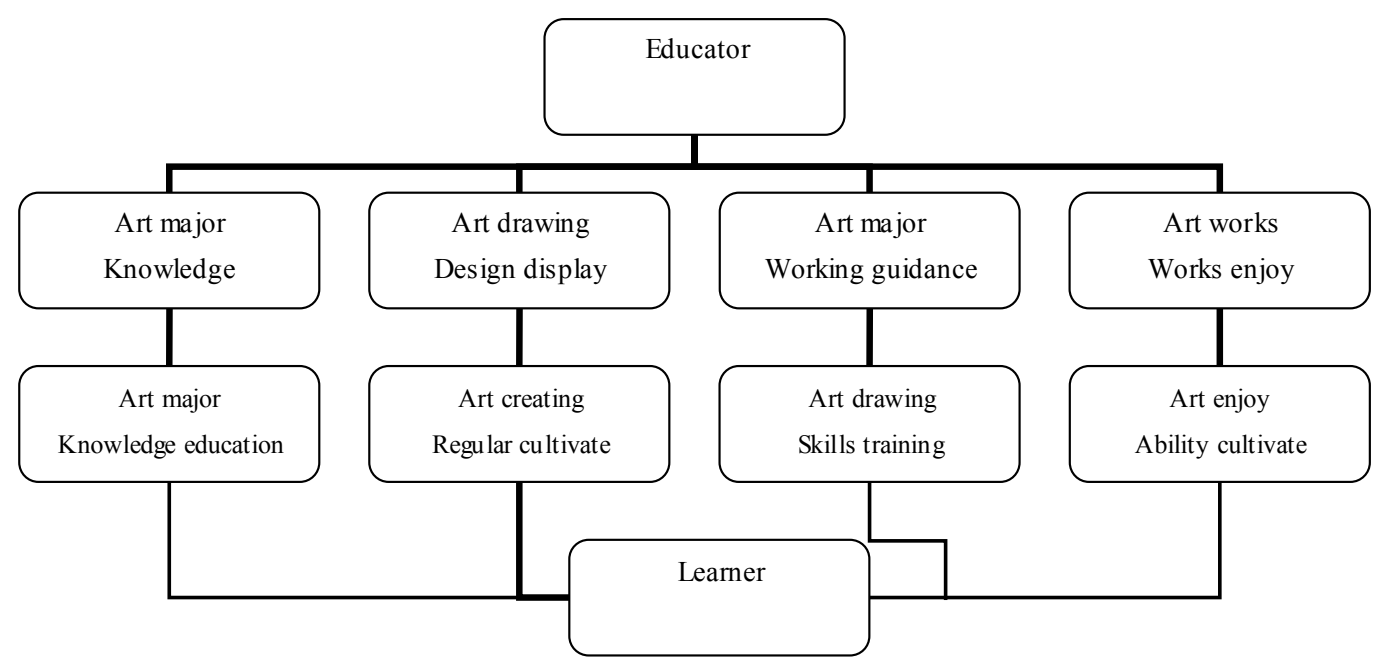

Chart 3: the teaching mode of "Dual structured"

The teaching process of traditional art "dual structured" teaching mode has the following stages: project creation establishment stage; educators subject teaching demonstration stage; learners' subject reference copy stage; learners subject creation analysis phase; learners subject creation 
study phase; comprehensive evaluation and educators learners feedback (as shown in chart 4)

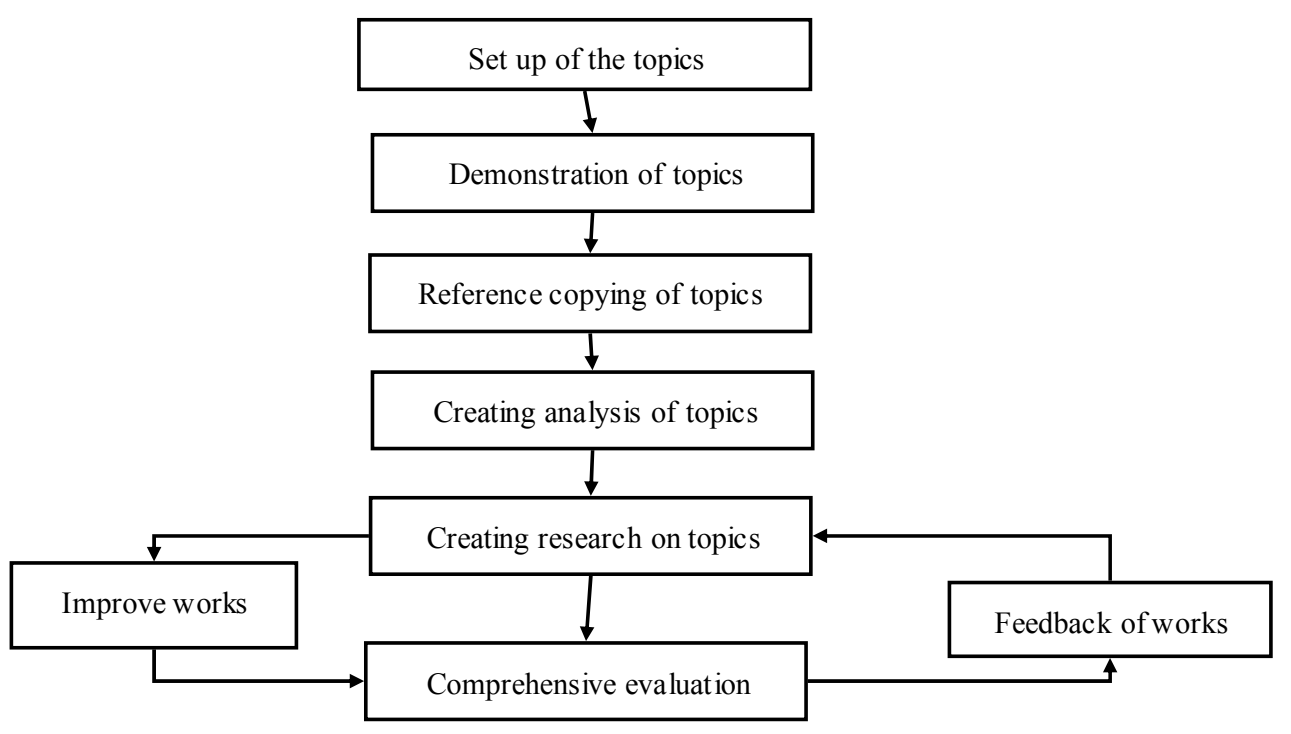

Chart 4: the teaching progress of "dual structured" teaching mode

\section{Computer aided art teaching mode of study}

Computer aided art teaching mode, "multiple structures "teaching mode, is different from the traditional arts "dual structured" teaching mode. The teaching mode breaks the traditional fine arts teaching and learning of" dual structure ", forms the educators, learners, digital network learning platform, virtual participants (virtual managers, experts, virtual classroom), such as "multiple structures".

"Multiple structured" teaching model sets the "digital network learning platform" as the carrier, by educators, learners, team members and virtual participants square building common form. "Multiple structured" teaching mode has the following characteristics: 1, the new mode has digital network Shared characteristic; 2, the new mode has the features of good effectiveness and high maneuverability; 3 , the new mode has the characteristics of a variety of ways to learn.

Computer digital technology provides art teaching the way of changing painting, the traditional arts teaching form of hand-painted has been replaced by the computer automatic drawing technology (as shown in chart 5).

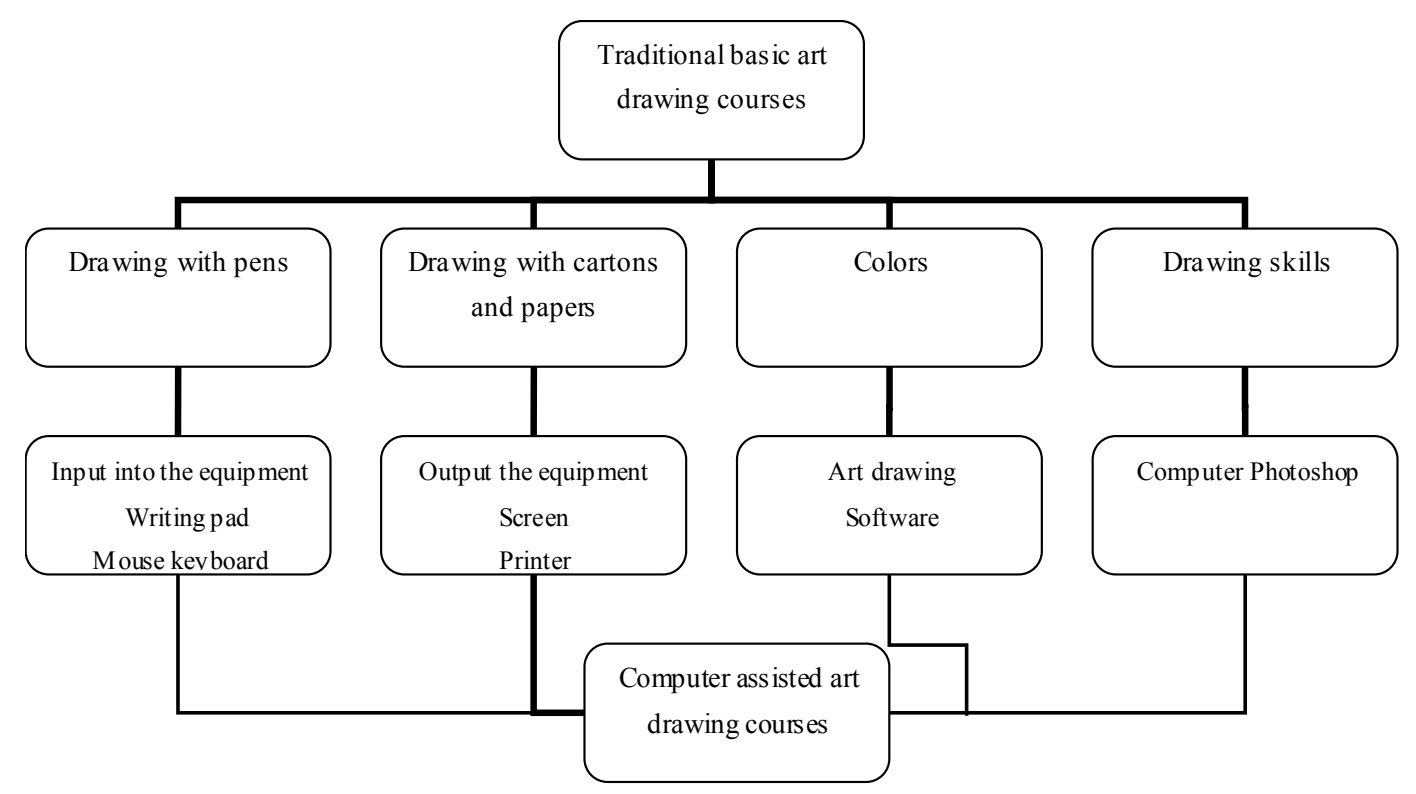

Chart 5: the relationship of traditional and computer assisted art teaching 


\section{Summary}

Information technology makes the teaching methods more flexible and various. It brakes the traditional teaching pattern of class teaching system, makes the individualized teaching mode, group cooperative teaching mode, online learning, online discussion possible. Information technology has changed teacher's role and function in the information society, changed the nature of the students' learning activities. Network has brought students to learn knowledge and develop opportunities and challenges. The students' active exploration spirit and creative ability can be to be able to make full use of.

\section{References}

[1] Chen Jianzhou, Current Situation Analysis and Countermeasure Research of Primary and Secondary School Education Informatization Characteristics of Network Education Resources[J]. China Educational Technology, 2001(7):21-25.

[2] Chen Xianjun, The pros and cons analysis of network teaching resources characteristics[J]. Network and resources, 2008:7-8.

[3] Huagn Zhiqiang, The research of intelligent education resource guide technology[J]. Present Education Technology, 2005:2-4.

[4] Yang Zongkai, Network education institute of standards and technology[M]. Beijing, Tsinghua University Press,2003.

[5] Yu Shenquan, Integration of information technology and curriculum - the network teaching mode and method[M]. Shanghai: Shanghai Educational Publishing House, 2005 